\title{
Assessing the Continuum of Care Pathway for Maternal Health in South Asia and Sub-Saharan Africa
}

\author{
Kavita Singh ${ }^{1,2}$, William T. Story ${ }^{1}$, and Allisyn C. Moran ${ }^{3}$ \\ ${ }^{1}$ MEASURE Evaluation/Carolina Population Center, University of North Carolina at Chapel Hill, \\ Chapel Hill, NC \\ 2Department of Maternal and Child Health, Gillings School of Global Public Health, University of \\ North Carolina at Chapel Hill, Chapel Hill, NC \\ ${ }^{3}$ Global Health Fellows Program II, United States Agency for International Development (USAID), \\ Washington, DC
}

\begin{abstract}
Objective-We assess how countries in regions of the world where maternal mortality is highest - South Asia and Sub-Saharan Africa - are performing with regards to providing women with vital elements of the continuum of care.
\end{abstract}

Methods-Using recent Demographic and Health Survey data from nine countries including 18,036 women, descriptive and multilevel regression analyses were conducted on four key elements of the continuum of care - at least one antenatal care visit, four or more antenatal care visits, delivery with a skilled birth attendant and postnatal checks for the mother within the first 24 hours since birth. Family planning counseling within a year of birth was also included in the descriptive analyses.

Results-Results indicated that a major drop-out (more than 50\%) occurs early on in the continuum of care between the first antenatal care visit and four or more antenatal care visits. Few women (less than 5\%) who do not receive any antenatal care go on to have a skilled delivery or receive postnatal care. Women who receive some or all the elements of the continuum of care have greater autonomy and are richer and more educated than women who receive none of the elements.

Conclusion-Understanding where drop-out occurs and who drops out can enable countries to better target interventions. Four or more ANC visits plays a pivotal role within the continuum of care and warrants more programmatic attention. Strategies to ensure that vital services are available to all women are essential in efforts to improve maternal health.

\section{Keywords}

Antenatal Care; Continuum of Care; Family Planning; Maternal Health; PNC; Skilled Delivery; South Asia; Sub-Saharan Africa 


\section{Introduction}

The continuum of care for maternal, newborn and child health, as defined by Kerber et al. [1] indicates that individuals should have access to key services throughout the life cycle including adolescence, pregnancy, childbirth, the postnatal period and childhood. The definition of the continuum of care is sometimes further narrowed to focus on pregnancy, childbirth and the postpartum period in an effort to prevent maternal and newborn mortality [2]. In such cases the goal of the continuum of care is to provide women with the reproductive health care they need before, during and after pregnancy and delivery and to provide newborns with the opportunity to grow into healthy children [1-4]. Emphasis is placed on a unified integrated approach for mothers and newborns and roles for facilitybased care, outreach and community-based or home care throughout the life cycle.

Mothers and newborns are particularly vulnerable during childbirth and the days immediately afterwards, thus the importance of services provided during these times. Many of the estimated 289,000 global maternal deaths [5] occur during labor, delivery and the immediate postpartum period. Neonatal deaths, estimated to be 2.9 million worldwide, now account for $44 \%$ of under five mortality [6]. In some settings up to half of newborn deaths occur on the very first day of life [7], and $46 \%$ of the estimated 2.6 million stillbirths occur during labor [8]. The continuum of care, thus, encompasses key elements of services including antenatal care (ANC), delivery with a skilled birth attendant (SBA) and postnatal care (PNC) within 24 hours for both mothers and newborns (either in a facility or at home). While many studies have examined ANC and delivery with a SBA (typically defined as with a doctor, midwife or nurse), PNC is a newer area of focus. In addition, postpartum family planning, defined as the initiation of family planning services within a year following childbirth [9], is an important area to consider. It is estimated that family planning has reduced maternal deaths by at least $40 \%$ in the past 20 years. [10]. Until recently postpartum family planning has received little attention as an element of the continuum of care, however the latest World Health Organization (WHO) PNC guidelines include a recommendation that family planning counseling and provision should be part of PNC [11]. South Asia and Sub-Saharan Africa are two regions of the world where improvements in the provision of the continuum of care are desperately needed. These two regions, together, account for 85.8\% of maternal deaths [5]. Neither region met Millennium Development Goal (MDG) 4, a two-thirds reduction in under-five mortality from 1990 to 2015, nor MDG 5, a three quarters reduction in maternal mortality from 1990 to 2015. In these two regions, large socioeconomic differentials in maternal and child health outcomes exist within countries. For example, poor women are 2.7 times less likely to deliver with a SBA compared to rich women [12].

The main objective of this paper is to quantitatively document coverage of key interventions along the continuum of care in selected countries in South Asia and Sub-Saharan Africa, specifically to assess where drop-outs in the pathway of services occur. A woman may drop out of the continuum of care pathway for many reasons including poverty, lack of access to the next service, preference or cultural factors. Only one known study has presented the continuum of care in a step-wise fashion as was done in this paper. This study, focused on Cambodia, found wide provincial-level variation (from 14\% to 96\%) in the proportion of 
women who received all three elements (at least one ANC visit, delivery with a SBA and PNC within 48 hours) of the continuum of care that were studied [2]. Our multi-country study examines four components of the continuum of care, including at least one ANC visit, four or more ANC visits, delivery with a SBA, and PNC within 24 hours for the mother. Family planning counseling within one year of birth was also explored for those countries that have this information available. The second objective of this paper is to document socioeconomic and demographic differentials comparing women who receive all or some elements of the continuum of care versus those who receive no elements.

\section{Data and Methods}

\section{Data}

Demographic and Health Survey (DHS) survey data were pooled for the nine Maternal and Child Health priority countries for the United States Agency for International Development (USAID) that had recent data (from 2010 onwards) on ANC, delivery with a SBA and PNC. The countries included Bangladesh, Nepal, Pakistan, Ethiopia, Malawi, Rwanda, Senegal, Tanzania and Uganda. All of the countries except Bangladesh also had information on family planning counseling in the past 12 months. Because this study relied on publicly available data with no identifying information, it was reviewed but exempted from needing ethics review approval by the Institutional Review Board (IRB) at the first author's affiliation.

Each DHS is a nationally representative population-based survey, and in all sampled households, women age 15-49 are eligible to participate in an individual questionnaire. The sample is typically based on a stratified two-stage cluster design whereby the first stage is the sample enumeration area (SEA) or cluster, generally drawn from Census files. In the second phase a sample of households is drawn from a list of households in each SEA. The sample is generally representative at the national level, regional (departments, states) level and by urban/rural residence [13]. Our study was focused on 18,036 women with a birth in the past year. (Table 1).

\section{Outcome Variables/Elements of the Continuum of Care}

There were two questions in the DHS that were used to determine if women received any ANC and if so, how many. Delivery with a SBA was defined as delivery attended by a doctor, midwife or nurse. Questions on PNC and timing of PNC were used to determine if a woman had a check (whether at home or in a facility) within 24 hours of birth. Three questions were used to determine whether a woman received family planning counseling within a year of birth 1) In the last 12 months, were you visited by a health extension worker (HEW)/community health worker (CHW) or others who talked to you about family planning? 2) In the last 12 months have you visited a health facility for care for yourself (or your children)? and 3) Did any staff member/HEW at the health facility speak to you about family planning methods? There were no specific questions on actual provision and counseling on family planning with the context of PNC. 


\section{Descriptive Presentation of the Continuum of Care}

We analyzed the continuum of care descriptively in three ways. First, data on use of the five services in the continuum - at least one ANC visit, four or more ANC visits, delivery with a SBA, PNC check within 24 hours for the mother, and family planning counseling within one year of birth were presented for each country and region. Data are also presented on early ANC, defined as having an ANC visit within the first trimester. Because information on timing of subsequent visits was unavailable, the early ANC variable was not included in the subsequent analyses because of the difficulty in determining the value of one early ANC visit without subsequent ANC visits (Table 2).

The second descriptive method was a depiction of the different combinations of maternal health services within the continuum of care that women are receiving by region (Table 3 ). This table illustrates which elements of the continuum of care are closely aligned and services that are most often missed. Studying combinations is also a method to understand places in the continuum where significant drop-out is occurring.

The third method was an illustration of a visual cascade of services within the continuum of care to indicate the proportions of women who move from one service to the next (Figures 1 and 2). These figures also indicate the points along the continuum where a large amount of drop-out occurs. Data on family planning counseling in the past year was presented in Table 2 and Figure 2 only. The reasons for this are to keep the main focus of the paper on a restricted time period from antenatal care to 24 hours postpartum.

\section{Regression Analysis}

The data were pooled from all nine countries, and multilevel multinominal logistic regression analysis was used to study socioeconomic and demographic factors associated with receiving all elements of the continuum (at least one ANC visit, four or more ANC visits, delivery with a SBA, and PNC within 24 hours for the mother), some elements, or no elements. A multilevel multinomial logistic regression model was employed using Stata's generalized linear latent and mixed models (gllamm) command to take advantage of the multilevel structure of the data and to account for clustered nature of the data [14]. By using multilevel analysis it was possible to determine whether, after accounting for differences and similarities among the countries, the variables of interest were associated with the outcome. A random intercepts model approach was used to account for the potential correlation between the continuum of care outcomes within each country by splitting the total error into two error components: one at the household level and one at the country level. Sampling weights were also applied.

Key variables that were studied were maternal age (15-19, 20-24, 25-34, or 35-49), parity $(1,2-3$, or 4 or more), education (none, primary, or secondary and greater), area of residence (urban or rural), wealth quintile, and women's decision-making (defined as being involved in decisions about one's own health either alone or jointly with a spouse). 


\section{Results}

Table 1 indicates the number of women included in this study by country. Table 2 contains information on each separate element of the continuum of care by country and region. For each country the most common service received was at least one ANC visit which varied from $43 \%$ in Ethiopia to $99 \%$ in Malawi. In many countries the proportion of women who received four or more ANC visits was less than half the proportion for one ANC visit. In seven of the nine countries the proportion of women who had a delivery with a SBA was higher than the proportion who had four or more ANC visits. Only $47 \%$ of women had their first ANC visit in the first trimester in South Asia, and this proportion was even lower at $24 \%$ in Sub-Saharan Africa. The proportion of women who received PNC within 24 hours ranged from 5\% in Ethiopia to 63\% in Senegal. The proportion of women who received family planning counseling in the past 12 months varied from 33\% in Nepal to 76\% in Rwanda. Regionally, Sub-Saharan African countries appeared to be performing slightly better in the areas of delivery with a SBA and family planning counseling within a year of birth compared to South Asian countries. On the other hand, South Asian countries appeared to be performing better in the area of PNC for mothers within 24 hours compared to SubSaharan African countries at $47 \%$ compared to $29 \%$, respectively.

Table 3 illustrates the different combinations of maternal health services along the continuum of care received by women by region. In South Asia $25 \%$ of women received all services compared to $14 \%$ in Sub-Saharan Africa. The proportion of women receiving none of the services was 16\% for women in South Asia and 12\% for women in Sub-Saharan Africa. The most common combinations of services were receiving only one ANC visit and no other services and receiving all services except four or more ANC visits. Delivery with a SBA without any ANC was uncommon at less than 5\% in South Asia and less than $1 \%$ in sub-Saharan Africa. Likewise, PNC was uncommon unless it was combined delivery with a SBA and at least one ANC visit.

Figure 1 depicts a visual presentation of women who remain in the continuum of care from one service to the next as well as the proportion who drop-out at each stage. Overall for the two regions combined $84 \%$ of women had at least one ANC visit, but there was a large drop at four or more ANC visits. The proportion of women who received one visit and who also received at least four visits was only 38\% (a 55\% decrease from the original 85\%). Only $28 \%$ of women had at least one ANC visit, four ANC visits and delivery with a SBA, but the proportion of women who dropped out between the later two steps was the smallest across the continuum (a 25\% decrease). Only 17\% of the original sample received all services up to PNC (a 40\% decrease from the previous step of delivery with a SBA). Comparisons between the pathways for Asia and Sub-Saharan Africa indicate that more women in the later sample had at least one ANC visit (87\% compared to 78\%) while more women in the former sample receive all elements of the continuum of care (25\% compared to $14 \%$ ).

Figure 2 presents the same continuum of care pathway, but also includes family planning counseling in the past year. The sample for Figure 2 was smaller because (as mentioned earlier) Bangladesh did not have the needed questions on family planning counseling in the past year. This figure is similar in that there was a large drop between at least one ANC visit 
and four or more visits. For the two regions combined only $11 \%$ of the initial sample received all services in the continuum of care through family planning counseling in the past year. A comparison of the two regions reveals that more women in the Asian sample received all the services through family planning counseling compared to women in the SubSaharan African sample (16\% versus 9\%).

In Table 4 descriptive statistics for the dependent and independent variables for the regression analysis are presented. About $13 \%$ of women in the sample received no services along the continuum of care, $70 \%$ received some, and $17 \%$ received all four services. Seventy-two percent of the sample represented Sub-Saharan Africa and 28\% represented South Asia. Eighty percent of the sample resided in rural areas, and the majority of the sample was within the ages of 20-34. Over three-quarters of the women in the sample had more than one child. Over one-third of women in the sample had no education, and $44 \%$ were in the two lowest wealth quintiles. Fifty-three percent of women in the sample were involved in decisions about their own health.

Table 5 contains the results of the multilevel multinomial logistic regression analysis. The odds ratios are presented for women receiving some of the elements of the continuum of care compared to those who received none, and women who received all of the elements of the continuum of care compared to those who received none. Findings indicated a strong relationship with both education and wealth. Compared to women in the poorest wealth quintile, women in the richest wealth quintile had a significantly greater odds of receiving all of the elements of the continuum versus none (OR=14.2; CI: 6.97, 28.83; $\mathrm{p}<0.001$ ). Residence was only significant when comparing women who received all versus none of the elements of the continuum of care with rural women having lower odds of receiving all the elements compared to urban women ( $\mathrm{OR}=0.42 ; \mathrm{CI}$ : $0.27,0.65 ; \mathrm{p}<0.001)$. Overall, women of higher parity had a significantly lower odds of receiving some or all of the elements of the continuum of care compared to primiparous women. Older women had a significantly higher odds of receiving some or all of the elements of the continuum of care compared to younger women. An interaction between age and parity was tested, but found not to be significant. Finally, the decision-making variable was positive in both models but only significant when comparing women who received some versus none of the elements of the continuum of care $(\mathrm{OR}=1.45 ; \mathrm{CI}: 1.21,1.71 ; \mathrm{p}<0.05)$.

\section{Discussion}

Each element of the continuum of care for maternal health provides essential and potentially lifesaving services, thus the importance of quantitatively assessing the current state of the continuum of care in regions of the world where the burden of maternal mortality is highest. The current study reveals that only a small subset of women in Sub-Saharan Africa and South Asia received all elements of the continuum of care, and these women tended to be the most educated, richest and women with a high degree of autonomy. Services, thus, need to be made more accessible to the poorest and least empowered women.

Facilitating women's ability to have four or more ANC visits is an important means to strengthen the continuum of care pathway. There was a large drop between the two earliest 
steps in the continuum of care - any ANC and four or more ANC visits. ANC is important in and of itself and it is also as a crucial link to other services as few women who do not receive ANC go on to have a delivery with a SBA or a PNC check. The connection between ANC and delivery with a SBA has also been found in other studies [15-18]. Frequent contact with health providers and educational messages from health workers may partly explain the link between four or more ANC visits and skilled delivery. ANC also provides an opportunity for health workers and pregnant women to discuss birth plans and options for emergency transport in case of a complication $[17,19]$.

Given the pivotal role of four or more ANC visits in the pathway of the continuum of care, low and middle income countries need to promote strategies and interventions to make such care more accessible. Community-based health workers can be used to help track the progress of women along the continuum of care and follow-up with individuals when appointments are missed [20,21]. Mobile phone communication may be a means of sending reminders and educational messages about the importance of ANC. A study in Zanzibar found that a mobile phone intervention was significantly associated with woman having at least four ANC visits [22]. Conditional cash transfers have been found to be effective in removing cost as a barrier to receiving adequate ANC services as well as delivery with a SBA $[23,24]$. Strategies to make ANC more accessible may also be helpful in making other maternal and newborn services more accessible as well.

PNC and postpartum family planning counseling are relatively newer focus areas for the global health community. While facility-based PNC following delivery with a SBA in a facility is a preferred strategy, home-based PNC for at-home births may be an intermediate strategy as countries work to increase proportions of deliveries with SBAs [25]. Health workers should be trained to include family planning counseling and provision during PNC visits as part of routine care.

Findings from the regression analysis indicated that the most wealthy and educated women as well as women with decision-making autonomy were the most likely to receive some or all elements along the continuum of care. We also found that older women were more likely to access services possibly due to their status in the household. Women of higher parity, however, were less likely to receive all or some of the elements of the continuum of care. These women may have trouble accessing services due to childcare or perhaps relied upon experiences from other pregnancies [26, 27]. Specific targeted messages and strategies may be needed for women of different socioeconomic status, ages and parities, and the promotion of gender equality may be an influential strategy in improving maternal health [28-30].

Overall results from the regression analysis support current global initiatives on increasing access to services for all women. USAID has outlined ten strategic drivers to end preventable maternal mortality and driver two is improving equity of access to and use of services by the most vulnerable [31]. Similarly the WHO's most recent recommendation on improving maternal and newborn health stress community mobilization and participation as well as community-organized transport schemes and partnerships with TBAs [32].

There were several limitations to this analysis. First, it was not possible to study the quality of services. For example, information about the quality of the ANC visits and whether all 
recommended components of care were provided at each visit was not available [33].

Another limitation was the inability to study the exact timing of the family planning counseling, and the fact that due to data availability we could only study counseling and not use of family planning. Furthermore, this study was descriptive and cross-sectional thus it was subject to recall bias, though such bias was minimized by focusing on women with a recent birth. Future studies should focus on subnational level differences so countries can assess which geographic or administrative areas need the most focus [2]. Despite the limitations findings from this study provide specific recommendations on how to strengthen the continuum of care in efforts to improve maternal health.

\section{Acknowledgments}

This study was funded by the United States Agency for International Development (USAID) through a cooperative agreement (GHA-A-00-08-00003-00) with MEASURE Evaluation. The views expressed in this paper do not necessarily reflect those of USAID. This work was also supported in part by an R24 Center Grant (R24 HD050924) and a T32 Training Grant (T32 HD007168) to the Carolina Population Center at the University of North Carolina at Chapel Hill.

\section{References}

1. Kerber K, de Graft J, Bhutta Z, Okong P, Starrs A, Lawn J. Continuum of care for maternal, newborn, and Child health: from slogan to service delivery. The Lancet. 2007; 370(9595):13581369.

2. Wang W, Hong R. Levels and determinants of continuum of care for maternal and newborn health in Cambodia-evidence from a population-based survey. BMC Pregnancy and Childbirth. 2015; 15(62)10.1186/s12884-015-0497-0

3. Lawn JE, Tinker A, Munjanja SP. Where is maternal and child health now? The Lancet. 2006; 368(9546):1474-1477.

4. Gill K, Pande R, Malhotra R. Women deliver for development. The Lancet. 2007; 370(9595):13471357.

5. WHO. Trends in Maternal Mortality: 1990 to 2013 Estimates by WHO, UNICEF, UNFPA, The World Bank and the United Nations Population Division. Geneva: WHO; 2014.

6. UNICEF. Estimates by the UN-Interagency Group for Child Mortality Estimation. New York: UNICEF; 2013. Levels and Trends in Child Mortality.

7. Lawn JE, Cousens S, Zupan J. for the Lancet Neonatal Survival Steering Committee. 4 Million neonatal deaths: When? Where? Why? The Lancet. 2005; 365(9462):891-900.

8. Lawn JE, Blencowe H, Pattinson R, Cousens S, Kumar R, Gardosi J, et al. Stillbirths: Where? When? Why? How to make the data count? The Lancet. 2011; 377(9775):1448-1463.

9. Gaffield ME, Egan S, Temmerman M. It's about time: WHO and partners release programming strategies for postpartum family planning. Glob Health Science and Practice. 2014; 2(1):4-9.

10. Cleland J, Conde-Agudelo A, Peterson H, Ross J, Tsui A. Contraception and Health. The Lancet. 2012; 380(9837):149-156.

11. WHO. Recommendations on the Care of the Newborn. Geneva: WHO; 2014.

12. UNICEF. State of the World's Children. 2014. [cited 2014 Aug 22]. Available from: http:// www.unicef.org/sowc2014/numbers/

13. ICF International. 2004-2012. Demographic and Health Surveys (various) [Datasets]. Calverton, Maryland: ICF International [Distributor]; 2012.

14. Rabe-Hesketh, S.; Skrondal, A. A Multilevel and Longitudinal Modeling Using Stata. 3. College Station, TX: Stata Press; 2012.

15. Stanton C, Blanc A, Croft T, Choi Y. Skilled Care at Birth in the Developing World: Progress to Date and Strategies for Expanding Coverage. Journal of Biosocial Science. 2007; 39(1):109-120. [PubMed: 16522226] 
16. Ensor T, Quigley P, Green C, Badru AR, Kaluba D, Siziya S. Knowledgeable Antenatal Care as a Pathway to Skilled delivery: Modelling the Interactions Between Use of Services and Knowledge in Zambia. Health Policy and Planning. 201310.1093/heapol/czt044

17. Guliani H, Sepehri A, Serieux J. What impact does contact with the prenatal care system have on women's use of facility delivery? Evidence from low-income countries. Social Science \& Medicine. 2012; 74(12):1882-1890. [PubMed: 22483706]

18. Adiwanou V, LeGrand T. Does antenatal care matter in the use of skilled birth attendance in rural Africa: A multi-country analysis. Social Science \& Medicine. 2013; 86:26-34. [PubMed: 23608091]

19. Magoma M, Requejo J, Campbell O, Cousens S, Merialdi M, Filippi V. The Effectiveness of Birth Plans in Increasing Use of Skilled Care at Delivery and Postnatal Care in Rural Tanzania: a Cluster Randomised Trial. Tropical Medicine and International Health. 2013; 18(4):435-443. [PubMed: 23383733]

20. Rai RK. Tracking women and children in a continuum of Reproductive, Maternal, Newborn, and Child Healthcare (RMNCH) in India. Journal of Epidemiology and Global Health. 2014; 4(3): 239-243. [PubMed: 25107660]

21. Osaki K, Hattori T, Kosen S. The role of home-based records in the establishment of a continuum of care for mothers, newborns, and children in Indonesia. Global Health Action. 2013; 6(1):1-12. [PubMed: 23651873]

22. Lund S, Nielsen BB, Hemed M, Boas IM, Said A, Said K, et al. Mobile phones improve antenatal care attendance in Zanzibar: a cluster randomized controlled trial. BMC Pregnancy and Childbirth. 2014; 14(29)10.1186/1471-2393-14-29

23. Lim S, Dandona L, Hoisington JA, James S, Hogan M, Gakidou E. India's Janani Suraksha Yojana, a conditional cash transfer programme to increase births in health facilities; an impact evaluation. The Lancet. 2010; 375(9730):2009-2023.

24. Glassman A, Duran D, Fleisher L, Singer D, Sturke R, Angeles G. Impact of Conditional Cash Transfers on Maternal and Newborn Health. Journal of Health Population and Nutrition. 2013; 4(Suppl 2):S48-S66.

25. World Health Organization (WHO), United Nations Children's Fund (UNICEF). Home visits for the newborn child: a strategy to improve survival. Geneva: WHO; 2009.

26. Gupta S, Yamada G, Mpembeni R, Frumence G, Callaghan-Koru JA, Stevenson R, et al. Factors Associated with Four or More Antenatal Care Visits and Its Decline among Pregnant Women in Tanzania between 1999 and 2010. PloS One. 2014; 9(7):e101893. [PubMed: 25036291]

27. Mathole T, Lindmark G, Majoko F, Ahlberg BM. A Qualitative Study of Women's Perspectives of Antenatal Care in a Rural Area of Zimbabwe. Midwifery. 2004; 20(2):122-132. [PubMed: 15177855]

28. Singh K, Bloom S, Haney E, Olorunsaiye C, Brodish P. Gender equality and childbirth in a health facility: Nigeria and MDG5. African Journal of Reproductive Health. 2012; 16(3):123-129. [PubMed: 23437506]

29. Fotso JC, Ezeh AC, Essendi H. Maternal health in resource-poor urban settings: how does women's autonomy influence the utilization of obstetric care services. Reproductive Health. 2009; 6(9)10.1186/1742-4755-6-9

30. Bloom SS, Wypij D, Das Gupta M. Dimensions of women's autonomy and the influence on maternal health care utilization in a North Indian city. Demography. 2001; 38(1):67-78. [PubMed: 11227846]

31. USAID. Evidence for Strategic Approaches. Washington, DC: USAID; 2015. Ending Preventable Maternal Mortality: USAID Maternal Health Vision for Action.

32. WHO. Recommendations on Health Promotion Interventions for Maternal and Newborn Health. Geneva: WHO; 2015.

33. Hodgins S, D'Agostino A. The quality-coverage gap in antenatal care: towards better measurement of effective coverage. Global Health Science and Practice. 2014; 2(2):173-181. 


\section{Significance}

A continuum of care approach for maternal health is being championed as a means to ensure women receive essential services during pregnancy, delivery and the postpartum period. This study, focused on countries in South Asia and Sub-Saharan Africa, is among the first that presents the continuum of care as pathway in order to assess where drop-out is occurring and to understand the characteristics of women not receiving the vital services they need. 
(a)

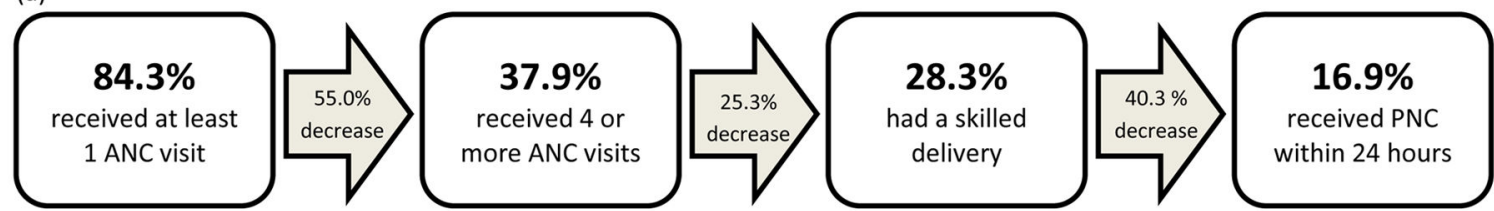

(b)

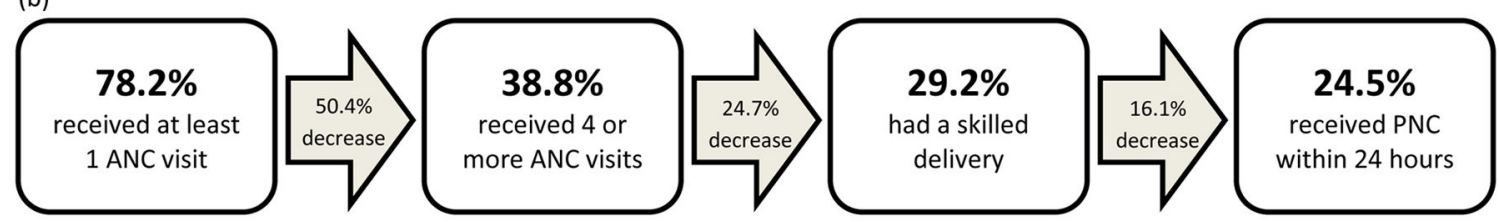

(c)

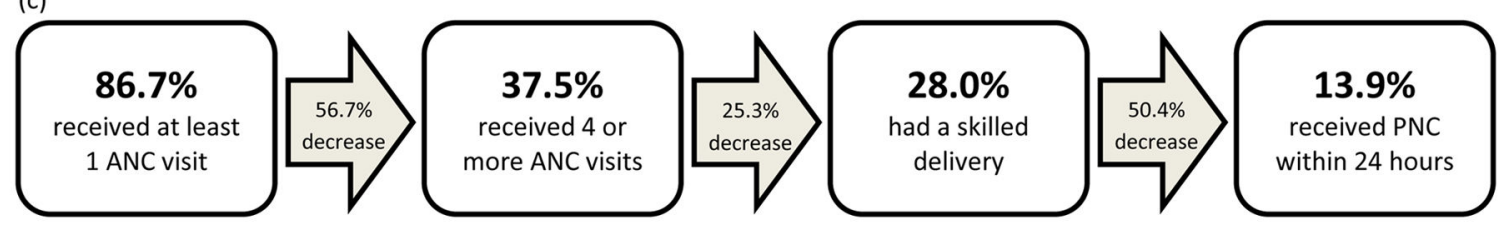

Figure 1.

Women who drop out of the continuum of care through PNC

(a) in all nine countries ( $\mathrm{N}=18,036)$, (b) in South Asian countries $(\mathrm{N}=5,030)$, and (c) in Sub-

Saharan African countries $(\mathrm{N}=13,006)$ 
(a)

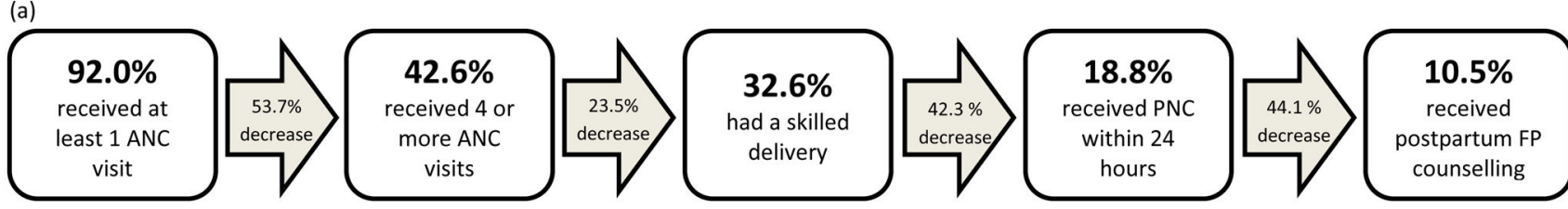

(b)
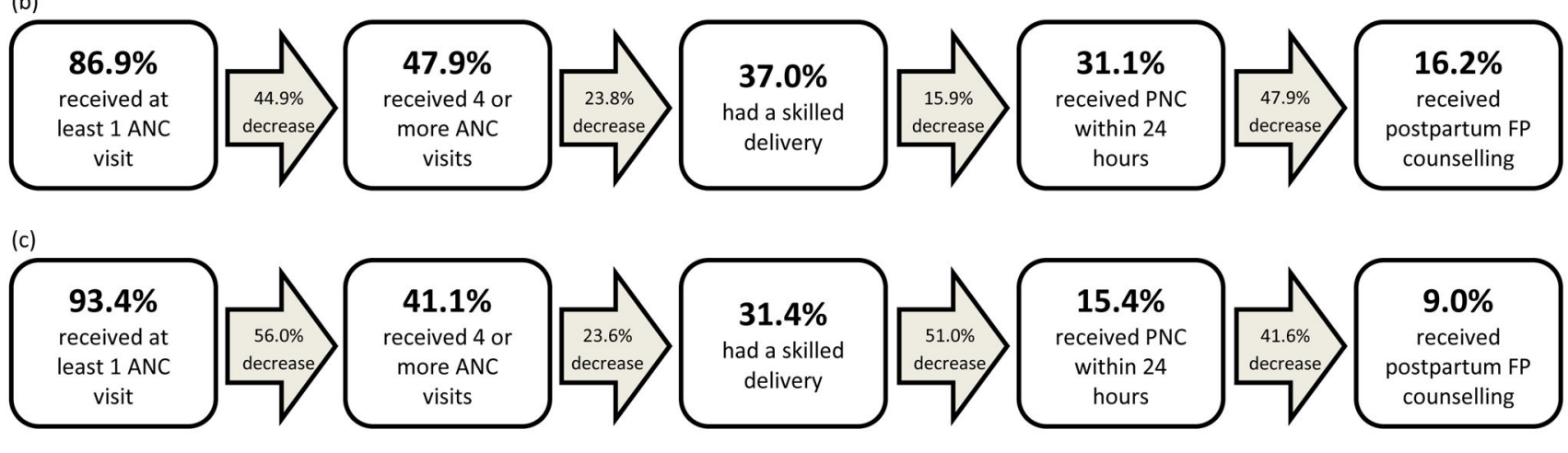

Figure 2.

Women who drop out of the continuum of care through family planning counseling within one year.

a) in all countries except Bangladesh $(\mathrm{N}=12,679)$, (b) in South Asian countries except

Bangladesh $(\mathrm{N}=2,499)$, and (c) in Sub-Saharan African countries $(\mathrm{N}=10,180)$ 


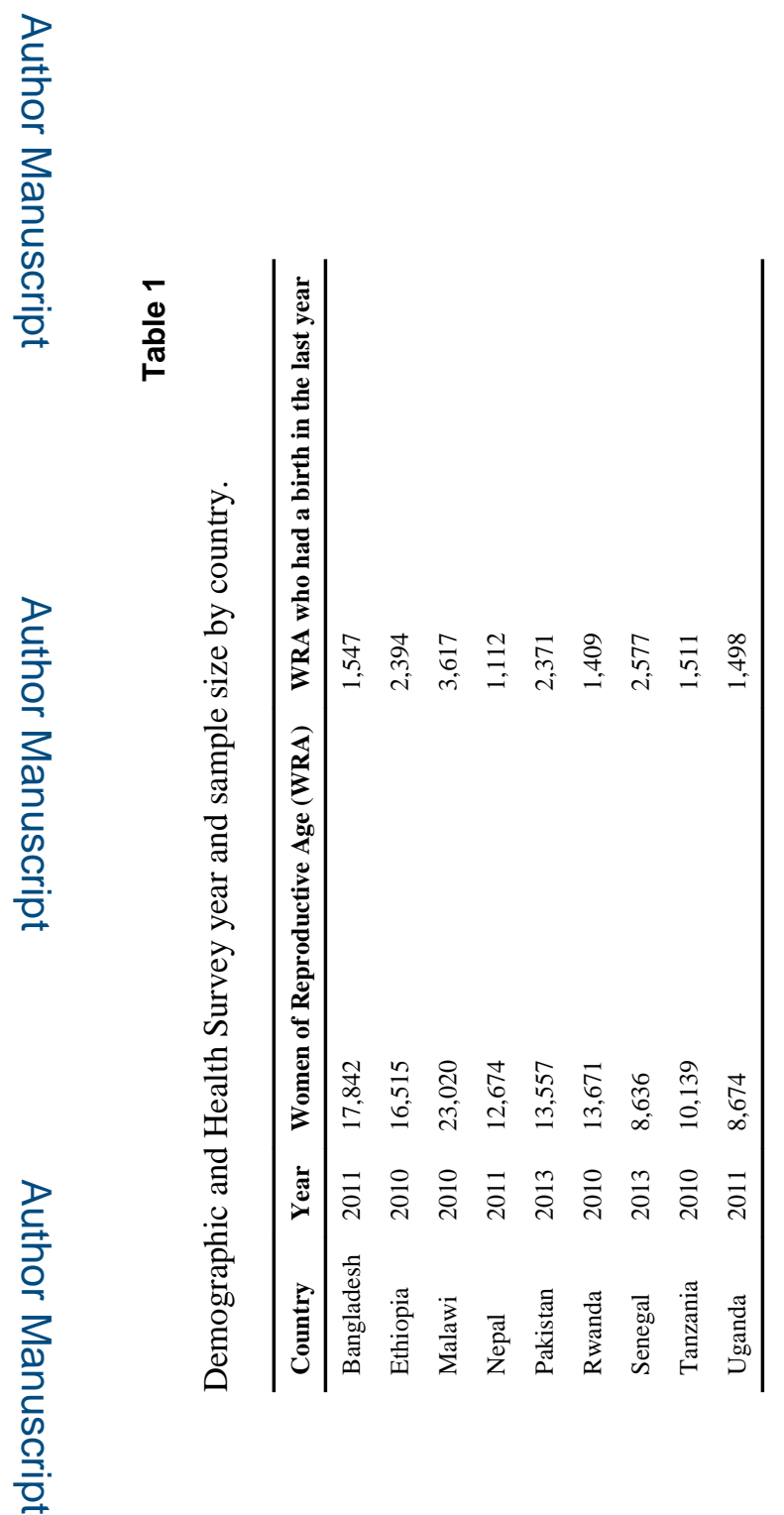

Matern Child Health J. Author manuscript; available in PMC 2017 February 01. 


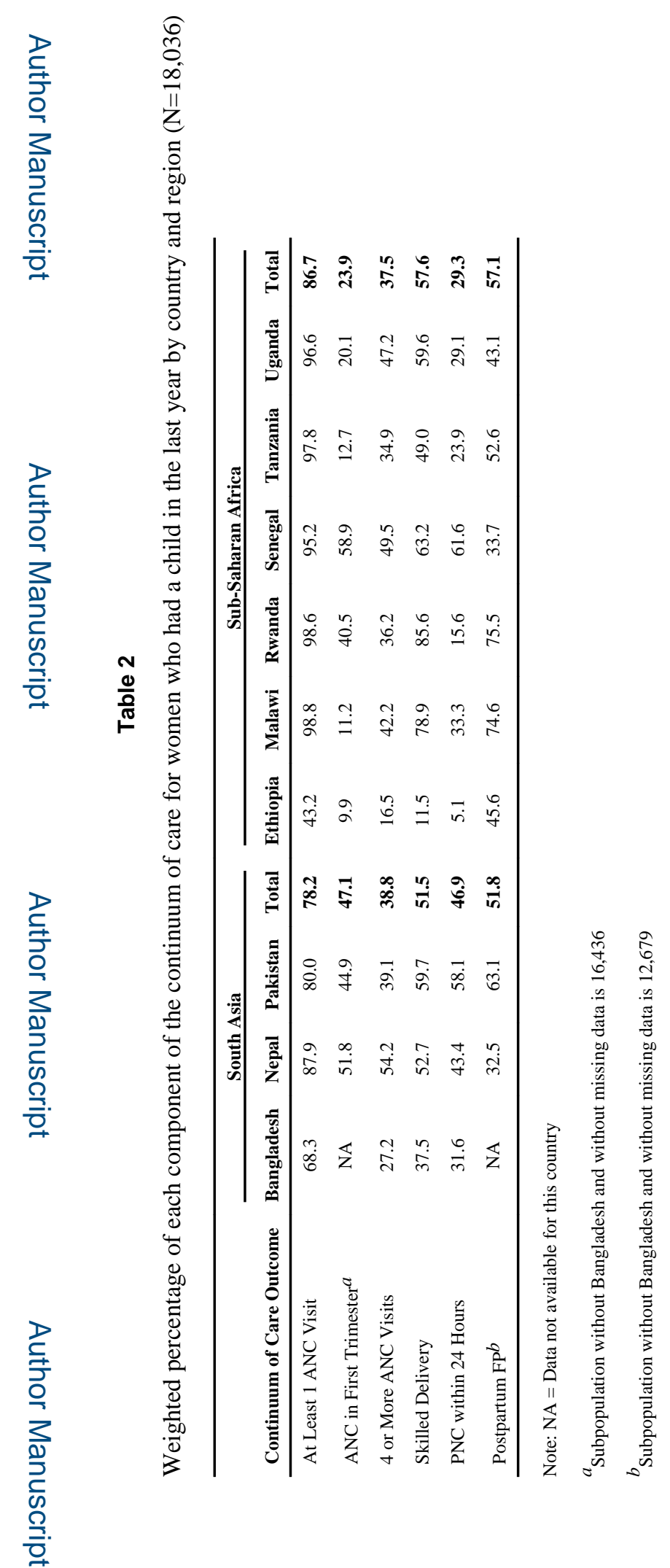

Matern Child Health J. Author manuscript; available in PMC 2017 February 01. 


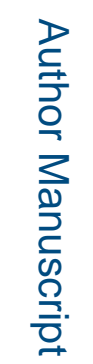

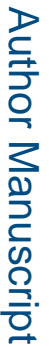

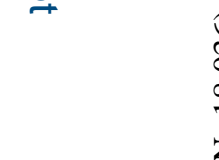
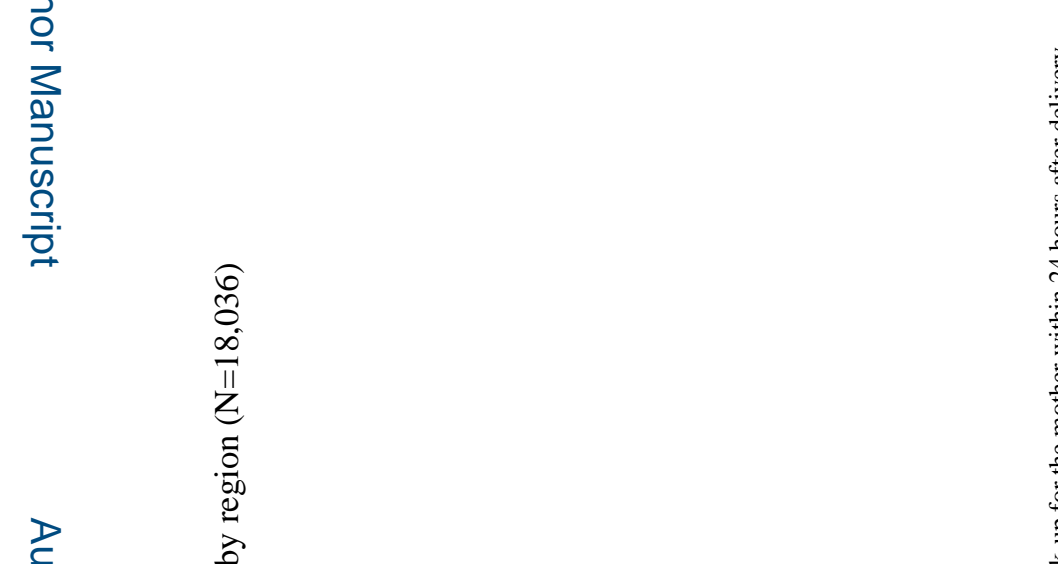

은

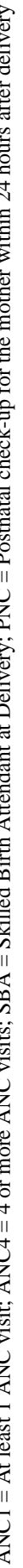

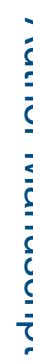

列

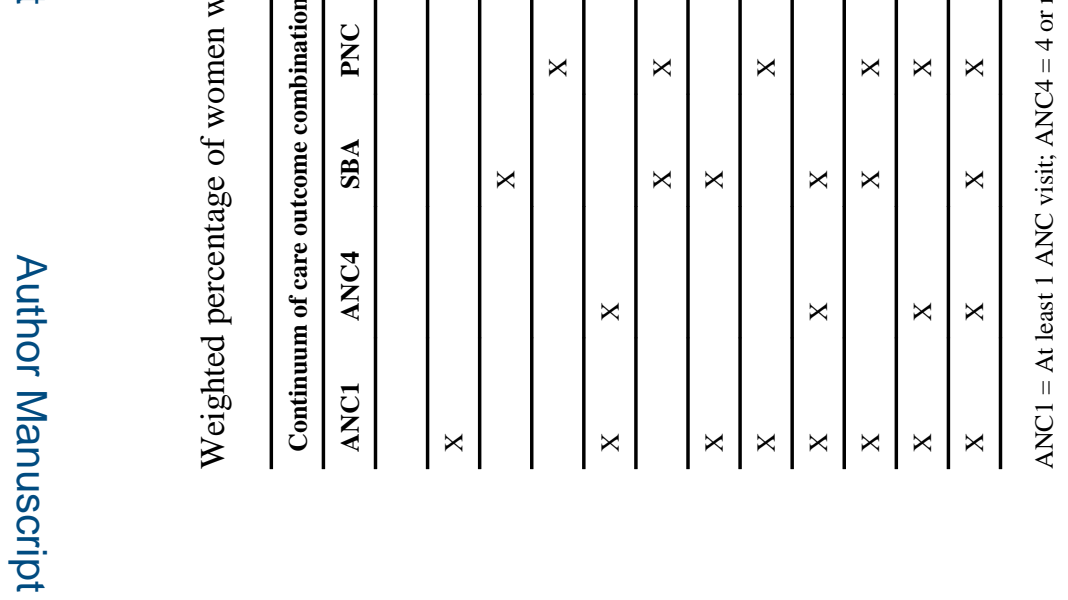

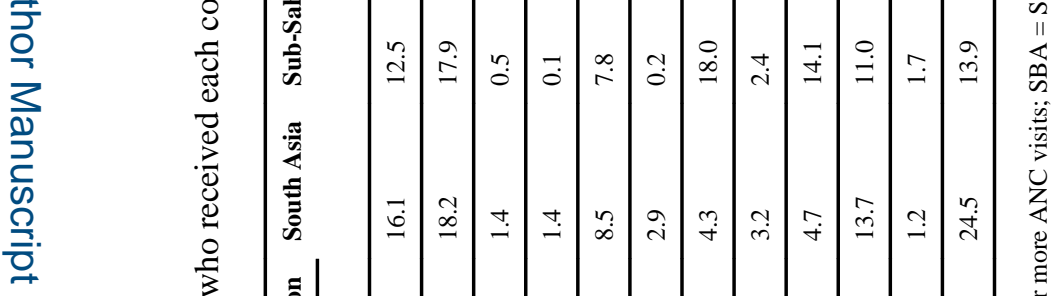

Matern Child Health J. Author manuscript; available in PMC 2017 February 01. 


\section{Table 4}

Weighted descriptive statistics for women who had a child in the last year by region $(\mathrm{N}=18,036)$

\begin{tabular}{|c|c|}
\hline Variables of interest & Percent \\
\hline \multicolumn{2}{|l|}{ Dependent variable } \\
\hline \multicolumn{2}{|l|}{ Continuum of care } \\
\hline None & 13.5 \\
\hline Some & 69.6 \\
\hline All & 16.9 \\
\hline \multicolumn{2}{|l|}{ Independent variables } \\
\hline \multicolumn{2}{|l|}{ Region } \\
\hline South Asia & 28.3 \\
\hline Sub-Saharan Africa & 71.7 \\
\hline \multicolumn{2}{|l|}{ Age } \\
\hline $15-19$ & 10.6 \\
\hline $20-24$ & 29.5 \\
\hline $25-34$ & 45.3 \\
\hline $35-49$ & 14.6 \\
\hline \multicolumn{2}{|l|}{ Parity } \\
\hline 1 & 21.6 \\
\hline $2-3$ & 37.6 \\
\hline $4+$ & 40.8 \\
\hline \multicolumn{2}{|l|}{ Education level } \\
\hline None & 38.0 \\
\hline Primary & 42.8 \\
\hline Secondary + & 19.2 \\
\hline \multicolumn{2}{|l|}{ Residence } \\
\hline Urban & 19.9 \\
\hline Rural & 80.1 \\
\hline \multicolumn{2}{|l|}{ Wealth quintile } \\
\hline Poorest & 22.0 \\
\hline Poorer & 22.3 \\
\hline Middle & 21.1 \\
\hline Richer & 18.2 \\
\hline Richest & 16.4 \\
\hline \multicolumn{2}{|c|}{ Decision-making about respondent's health care } \\
\hline Wife not involved & 47.4 \\
\hline Wife involved & 52.6 \\
\hline
\end{tabular}


Table 5

Multilevel multinomial logistic regression results of factors associated with the continuum of care $(\mathrm{N}=18,036)$

\begin{tabular}{|c|c|c|}
\hline \multirow[b]{2}{*}{ Characteristic } & \multicolumn{2}{|l|}{ Continuum of care } \\
\hline & $\begin{array}{l}\text { Some vs none } \\
\text { OR }(95 \% \mathrm{CI})\end{array}$ & $\begin{array}{l}\text { All vs none } \\
\text { OR }(95 \% \mathrm{CI})\end{array}$ \\
\hline \multicolumn{3}{|l|}{ Fixed effects } \\
\hline \multicolumn{3}{|l|}{ Age } \\
\hline $15-19$ & 1.00 & 1.00 \\
\hline $20-24$ & $1.48(1.30,1.69)^{* * *}$ & $1.75(1.52,2.26)^{* * *}$ \\
\hline $25-34$ & $1.35(1.00,1.82)$ & $2.09(1.24,3.51)^{* *}$ \\
\hline $35-49$ & $1.41(1.10,1.83)^{* *}$ & $2.86(1.88,4.36)^{* * *}$ \\
\hline \multicolumn{3}{|l|}{ Parity } \\
\hline 1 & 1.00 & 1.00 \\
\hline $2-3$ & $0.56(0.44,0.73)^{* * *}$ & $0.35(0.25,0.50)^{* * *}$ \\
\hline $4+$ & $0.45(0.24,0.86)^{*}$ & $0.17(0.08,0.36)^{* * *}$ \\
\hline \multicolumn{3}{|l|}{ Education level } \\
\hline None & 1.00 & 1.00 \\
\hline Primary & $1.83(1.53,2.20)^{* * *}$ & $1.45(1.04,2.02)^{*}$ \\
\hline Secondary + & $3.68(2.70,5.01)^{* * *}$ & $5.99(2.68,13.38)^{* * *}$ \\
\hline \multicolumn{3}{|l|}{ Residence } \\
\hline Urban & 1.00 & 1.00 \\
\hline Rural & $0.81(0.67,0.97)^{*}$ & $0.42(0.27,0.65)^{* * *}$ \\
\hline \multicolumn{3}{|l|}{ Wealth quintile } \\
\hline Poorest & 1.00 & 1.00 \\
\hline Poorer & $1.44(1.17,1.77)^{* * *}$ & $1.82(1.29,2.56)^{* * *}$ \\
\hline Middle & $2.20(1.63,2.99)^{* * *}$ & $3.58(2.13,6.02)^{* * *}$ \\
\hline Richer & $2.85(2.16,3.74)^{* * *}$ & $5.89(3.29,10.54)^{* * *}$ \\
\hline Richest & $5.79(4.24,7.91)^{* * *}$ & $14.18(6.97,28.83)^{* * *}$ \\
\hline \multicolumn{3}{|c|}{ Decision-making about respondent's health care } \\
\hline Wife not involved & 1.00 & 1.00 \\
\hline Wife involved & $1.45(1.21,1.74)^{*}$ & $1.12(0.89,1.42)$ \\
\hline Constant & $6.95(3.97,12.15)^{* * *}$ & $2.11(0.76,5.82)$ \\
\hline \multicolumn{3}{|l|}{ Random effects $^{a}$} \\
\hline Country-level variance (SE) ${ }^{b}$ & $2.67(0.52)^{* * *}$ & \\
\hline Log likelihood & -11321 & \\
\hline Log likelihood ratio test $\left(\chi^{2}\right)^{c}$ & $2855.71^{* * *}$ & \\
\hline \multicolumn{3}{|l|}{$\mathrm{p}<0.05$} \\
\hline \multicolumn{3}{|l|}{$\mathrm{p}<0.01$} \\
\hline $\mathrm{p}<0.001$ & & \\
\hline
\end{tabular}


${ }^{a}$ We assume that the country-level random effects are equal for "Some" and "All" categories; therefore, only one variance estimate is reported for the model.

${ }^{b}$ Significance of random effects evaluated by comparing model with a similar one in which random effects have been constrained to be zero.

${ }^{c}$ Compared to null model with no covariates. 